\title{
Genetic Regulation of Immunoglobulin and Specific Antibody Levels in Twins Reared Apart
}

Peter F. Kohler, Victor J. Rivera, Elke D. Eckert, Thomas J. Bouchard, Jr., and Leonard L. Heston

Division of Clinical Immunology, Department of Medicine, University of Colorado Medical School, Denver, Colorado 80262 ,

Department of Psychiatry, University of Minnesota Medical School, Minneapolis, Minnesota 55414,

and Department of Psychology, University of Minnesota, Minneapolis, Minnesota 55455

\begin{abstract}
We studied the effect of the same genetic but different environmental factors on total immunoglobulin and specific antibody levels in twins reared apart. Sera were analyzed from 26 monozygotic (MZ) and 10 dizygotic (DZ) twin pairs, who were separated on average 2 mo after birth and reared apart. Total IgM, IgG, and IgA were measured by single radial diffusion. Specific antibodies of each isotype to tetanus toxoid, and to polyvalent and type 14 pneumococcal capsular polysaccharides were measured by a solid-phase antigen-enzyme-labeled antiIg immunoassay. One-way analysis of variance showed intrapair total Ig and antibody levels to be more highly correlated in MZ compared with DZ twins. Our results indicate that genetic factors are more important than environment in regulating these humoral immune responses.
\end{abstract}

\section{Introduction}

Total Ig and specific antibody (Ab) levels are influenced by both genetic and environmental factors. In rodents, the magnitude of the antibody response to defined antigens is controlled by immune response genes in the major histocompatibility complex $(1,2)$. Rats reared in a germ-free environment with minimal antigenic exposure have very low total Ig levels, which only increase after exposure to normal environmental antigens (3). In humans, the relative contribution of genetic compared with environmental factors is unknown. Limited information is available on how these factors interact in determining the quality and quantity of the humoral immune response. Studies of conventional twins, who share similar environments, have shown that total Ig levels correlate more closely in monozygotic $(\mathrm{MZ})^{1}$ than dizygotic (DZ) twins, indicating a genetic influence (4-6). Our investigation was done to determine the effect of the same genetic but dissimilar environmental backgrounds on Ig- and isotype-specific antibody levels through utilization of twins separated soon after birth and reared apart. Our results indicate that genes are more

Dr. Rivera's present address is University of Popayon Medical School, Popayon, Columbia, South America. Address reprint request to Dr. Kohler, B164, University of Colorado Medical School, Denver, CO 80262.

Received for publication 21 May 1984 and in revised form 7 November 1984.

1. Abbreviations used in this paper: DZ, dizygotic; EIA, enzyme immunosorbent assay; MZ, monozygotic; Pn, pneumococcal.

J. Clin. Invest.

(C) The American Society for Clinical Investigation, Inc.

0021-9738/85/03/883/06 $\$ 1.00$

Volume 75, March 1985, 883-888 important than environment in determining these humoral immune responses.

\section{Methods}

Twins reared apart. Sera from 26 pairs of $\mathrm{MZ}$ twins reared apart were evaluated (7). Included in this group were one MZ pair from a set of triplets (MZ sisters and a brother), and three pairs from a set of $M Z$ male triplets. There were 12 female and 14 male MZ pairs, ranging in age from 11 to $58 \mathrm{yr}$. Sera were collected in Minneapolis from both members of each pair simultaneously, stored within $48 \mathrm{~h}$ at $-70^{\circ} \mathrm{C}$, shipped to Denver on dry ice, and again stored at $-70^{\circ} \mathrm{C}$. Two $\mathrm{MZ}$ female twins were concordant for adult onset diabetes mellitus and two MZ male twin pairs were concordant for childhood onset asthma. One MZ female pair was concordant for Hashimoto's thyroiditis and one was discordant for thyroid cancer. Sera from 10 pairs of $\mathrm{DZ}$ twins reared apart, including 2 pairs from the triplet set of $\mathrm{MZ}$ sisters and a brother, were similarly collected and stored. In the DZ group, there were five female and three male pairs, plus the two female-male pairs from the triplet set. Their ages ranged from 30 to $55 \mathrm{yr}$. One DZ male pair was concordant for adult onset asthma and two pairs of DZ female twins were discordant, one for rheumatoid arthritis, and one for multiple sclerosis.

The average age at time of separation was 2 mo with a range from birth to $4 \mathrm{yr}$. One pair was black. The others were all Caucasian. Zygosity diagnosis was based on analyses of eight blood type systems, four serum proteins, six erythrocyte enzymes, fingerprint ridgecount, ponderal index, and cephalic index (8).

Ig quantitation. Concentrations of IgG, IgA, and IgM were determined by single radial immunodiffusion using commercial plates (Immunoplates; Calbiochem-Behring Corp., La Jolla, CA). The experimental variation on repeated determinations of these same serums was under $15 \%$.

Isotype-specific antibody quantitation. An enzyme immunosorbent assay (EIA) was developed to determine isotype-specific (IgG, IgA, and IgM) antibody to tetanus toxoid and pneumococcal (Pn) capsular polysaccharides. Fluid tetanus toxoid, $200 \mu \mathrm{l}$ of a 1:50 dilution of Purogen (Wyeth Laboratories, Philadelphia, PA) in phosphate-buffered saline (PBS; $0.01 \mathrm{M}$ phosphate, $\mathrm{pH}$ 7.2), was adsorbed to 96-well microtiter plates (Linbro, Flow Laboratories, McLean, VA). Adsorbtion of Pn polysaccharide was done by first activating polyvalent $\mathrm{Pn}$ (Pneumovax; Merck, Sharp and Dome, Rahway, NJ) or type 14 Pn (Lederle Laboratories, Pearl River, NY) polysaccharide with cyanuric chloride, next crosslinking the Pn to poly L-lysine (Sigma Chemical Co., St. Louis, MO), and then coating onto microtiter plates following the method of Gray (9). The coating concentration for the individual polysaccharides was $1 \mu \mathrm{g} / \mathrm{ml}$ in PBS.

Sera were diluted $10^{-3}$ in PBS containing $0.05 \%$ Brij detergent, and 200- $\mu \mathrm{l}$ aliquots were incubated in the antigen-coated wells for $16-$ $18 \mathrm{~h}$ at room temperature. The wells were washed extensively, and then horseradish peroxidase-labeled monospecific goat IgG antibody to human IgG, IgA, or IgM (Tago, Burlingame, CA) were added at concentrations of $500 \mathrm{ng} / \mathrm{ml}$ for $1 \mathrm{~h}$ at $23^{\circ} \mathrm{C}$. After washing, substrate was added for $1 \mathrm{~h}$ and the reaction stopped by addition of $50 \mu \mathrm{l} 4 \mathrm{~N}$ sulfuric acid, and the OD at $492 \mathrm{~nm}$ was determined in an automatic spectrophotometer (Flow Laboratories). 
Paired twin sera were run in duplicate in adjacent wells for each assay without knowledge of zygosity. Total Igs were quantitated in milligrams per milliliter and isotype-specific antibody titers in relative OD units by relating all determinations to a standard serum obtained from a 26-yr-old white male physician who had been immunized with polyvalent Pn vaccine (Pneumovax) 4 wk previously and with tetanus toxoid in childhood. The standard serum was included on all antibody assays and assigned a titer of $100 \mathrm{OD}$ units. This standard serum contained $84 \mu \mathrm{g} / \mathrm{ml}$ of IgG anti-tetanus toxoid antibody as determined with a solid-phase radioimmunoassay by Dr. A. Saxon (UCLA Medical School, Los Angeles, CA) and $190.7 \mu \mathrm{g} / \mathrm{ml}$ total (IgG, IgA, and IgM) antibody to 12 capsular polysaccharides present in the polyvalent Pn vaccine (Pneumovax) and $10.7 \mu \mathrm{g} / \mathrm{ml}$ total antibody to type 14 polysaccharide as determined by the Farr ammonium sulfate assay,
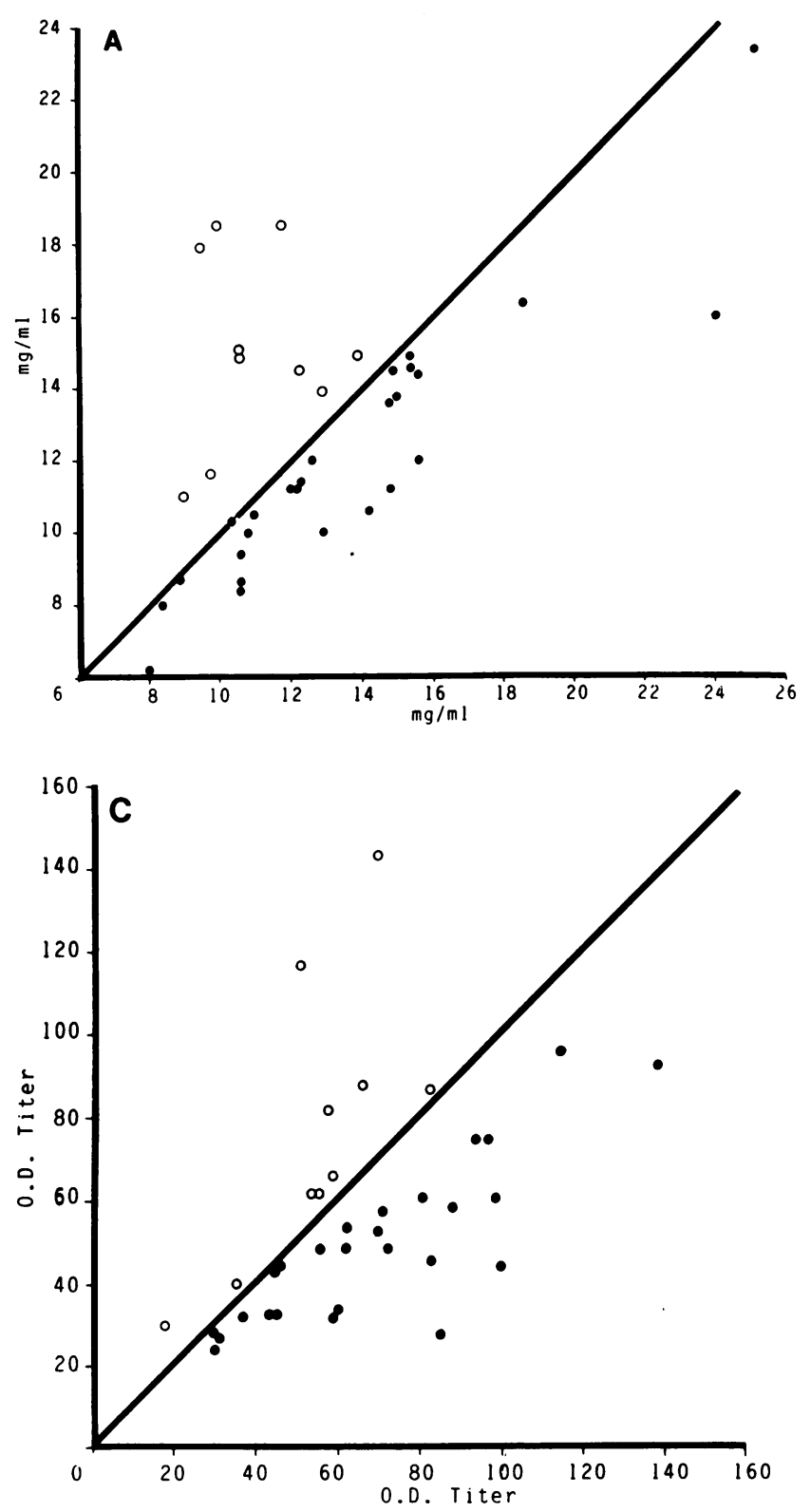

Figure 1. Comparison of IgG in twins reared apart. DZ (0) results are in the upper left and $\mathrm{MZ}(\bullet)$ in the lower right of each scatter diagram. The higher value in each $\mathrm{DZ}$ pair is plotted on the ordinate and in each $\mathrm{MZ}$ pair on the abscissa. $(A)$ Total Ig. DZ: $r,-0.40 ; F$, $0.43 ; P$, NS. MZ: $r, 0.82 ; F, 9.9 ; P<0.001$. (B) IgG anti-tetanus toxoid. DZ: $r, 0.27(0.17) ; F, 1.75$ (1.44); $P$, NS (NS). MZ: $r, 0.72$ (0.63); $F, 6.09$ (4.37); $P<0.001(<0.001)$. (C) IgG anti-polyvalent courtesy of Dr. G. Schiffman (State University of New York Downstate Medical School, Brooklyn, New York).

Specific activity. The specific activity for antibody of each isotype was obtained by dividing the relative OD titer by the concentration of IgG in milligrams per 10 milliliters and IgA and IgM in milligrams per milliliter. These concentrations were arbitrarily used to yield specific activities which approximated the OD titer values.

The experimental variation in the EIA antibody determinations was $<10 \%$ for the 3 isotypes and 3 antigens in repeat assays on different days on 13 sets of twin sera run in duplicate. Variability of the EIA was determined by dividing the replicate (between times) variance by the total (between individual) variance. Variation in duplicate results on the same serum at the same time was $<5 \%$.

Statistical analysis. Total Ig and isotype-specific antibody titers
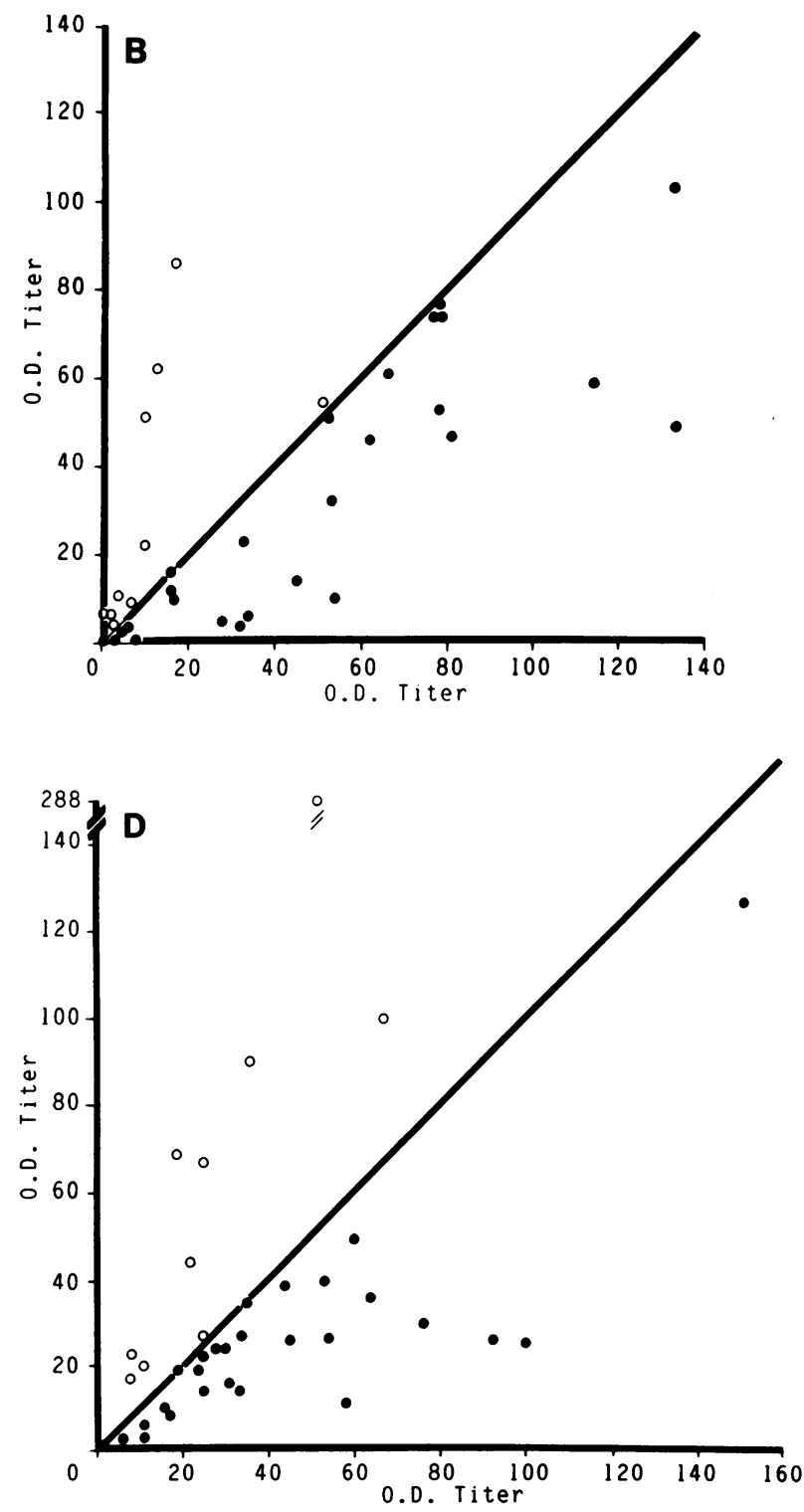

Pn. DZ: $r, 0.37$ (0.06); $F, 2.17$ (1.13); $P$, NS (NS). MZ: $r, 0.52(0.61)$; $F$, 3.20 (4.10); $P<0.01(<0.001)$. (D) IgG anti-type 14 Pn. DZ: $r$, 0.17 (0.08); $F, 1.40$ (1.18); $P$, NS (NS). MZ: $r, 0.62(0.55) ; F, 4.11$ (3.48); $P<0.001(<0.01) . r$, intratwin pair correlation coefficient; $F$, $F$-ratio; $P$, significance. The specific activity results are shown in parenthesis. 
were evaluated by one-way analysis of variance of the paired twin and triplet sera counting the $M Z$ triplets (individuals $a, b$, and $c$ ) as three pairs, i.e., $a-b, b-c$, and $a-c$, and the MZ-DZ triplets as one $M Z$ pair $(a-c)$ and two $\mathrm{DZ}$ pairs (a-b and b-c). The results in the $26 \mathrm{MZ}$ pairs are depicted in the lower right half and the $D Z$ pairs in the upper left half of the scatter diagrams which follow. One-way analysis of variance yields the "intraclass correlation" which, for identical twins reared apart, is a direct estimate of heritability, provided that environments are uncorrelated (10). The intraclass correlation coefficients for the 21 quantifiable variables ( 3 total Igs, 9 antibody titers with the 3 isotypes and 3 antigens; and 9 specific antibody activity titers) were obtained by dividing the mean square variance between (MSB) minus the mean square variance within (MSW) twin pairs by the MSB plus MSW variances and the $F$-ratio by dividing the MSB variance by the MSW
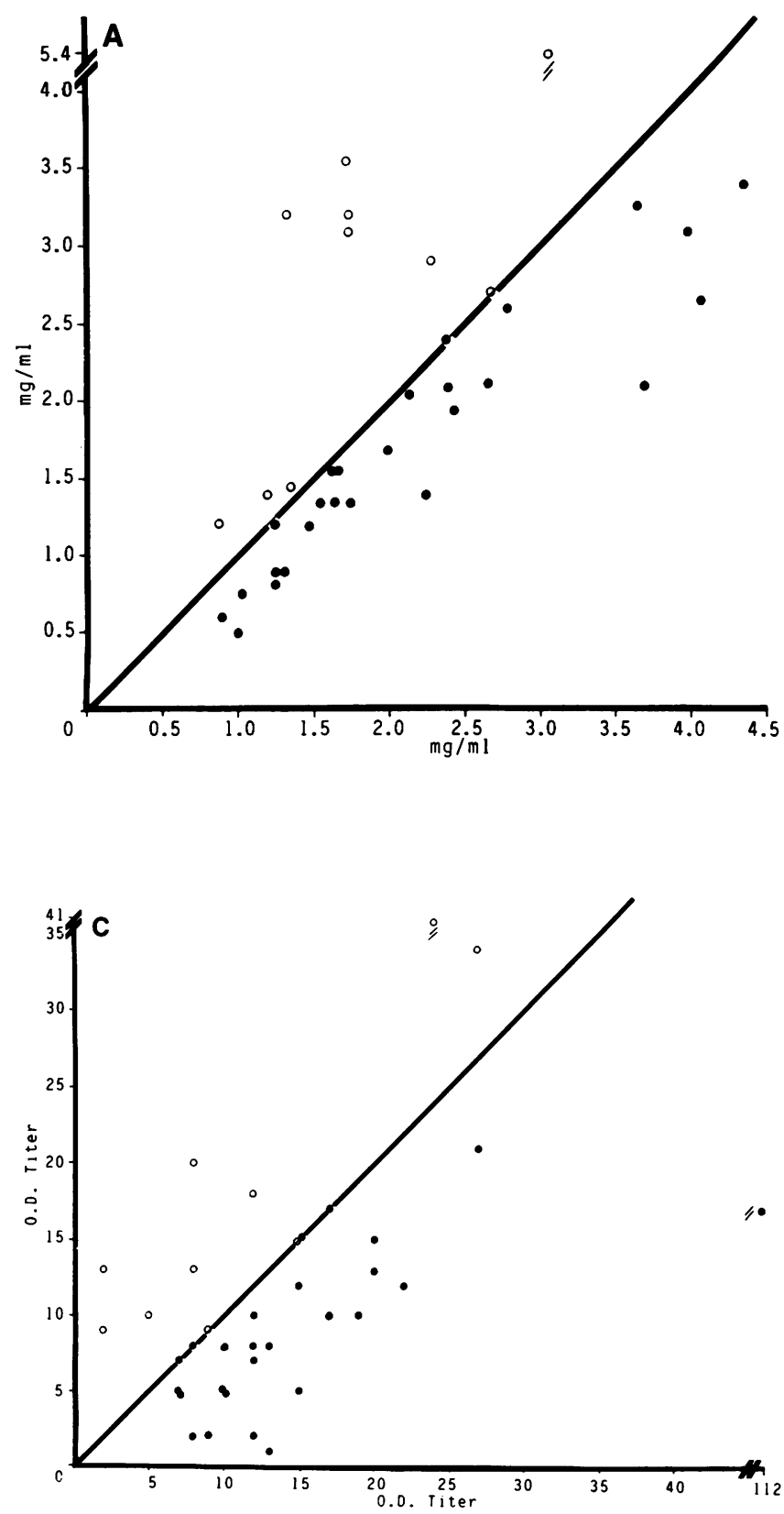

Figure 2. Comparison of IgA in twins reared apart. See Fig. 1 for explanation of symbols. $(A)$ Total IgA. DZ: $r, 0.34 ; F, 2.07 ; P$, NS. MZ: $r, 0.80 ; F, 9.13 ; P<0.001$. (B) IgA anti-tetanus toxoid. DZ: $r$, 0.17 (0.24); $F, 1.42$ (1.63); $P$, NS (NS). MZ: $r, 0.25(0.53) ; F, 1.68$ (3.26); $P$, NS (<0.05). (C) IgA anti-polyvalent Pn. DZ: $r, 0.66$ (0.24); variance. Calculations were done on a programmable desk calculator (Compucorp model 145E; Computer Design Corp., Los Angeles; CA) and significance values obtained from $F$-ratio and correlation coefficient tables.

\section{Results}

Total serum Ig concentrations. The distribution of Ig concentrations in the $\mathrm{MZ}$ and $\mathrm{DZ}$ pairs are shown in Figs. $1 A, 2 A$, and $3 \mathrm{~A}$. In the $\mathrm{MZ}$ twins reared apart, the within pair correlation coefficients were highly significant for all three isotypes: $\operatorname{IgG}(r=0.82, P<0.001), \operatorname{IgA}(r=0.80, P<0.001)$, and $\operatorname{IgM}(r=0.82, P<0.001)$. By contrast, in the $\mathrm{DZ}$ twins reared apart, the total concentrations of individual Igs were
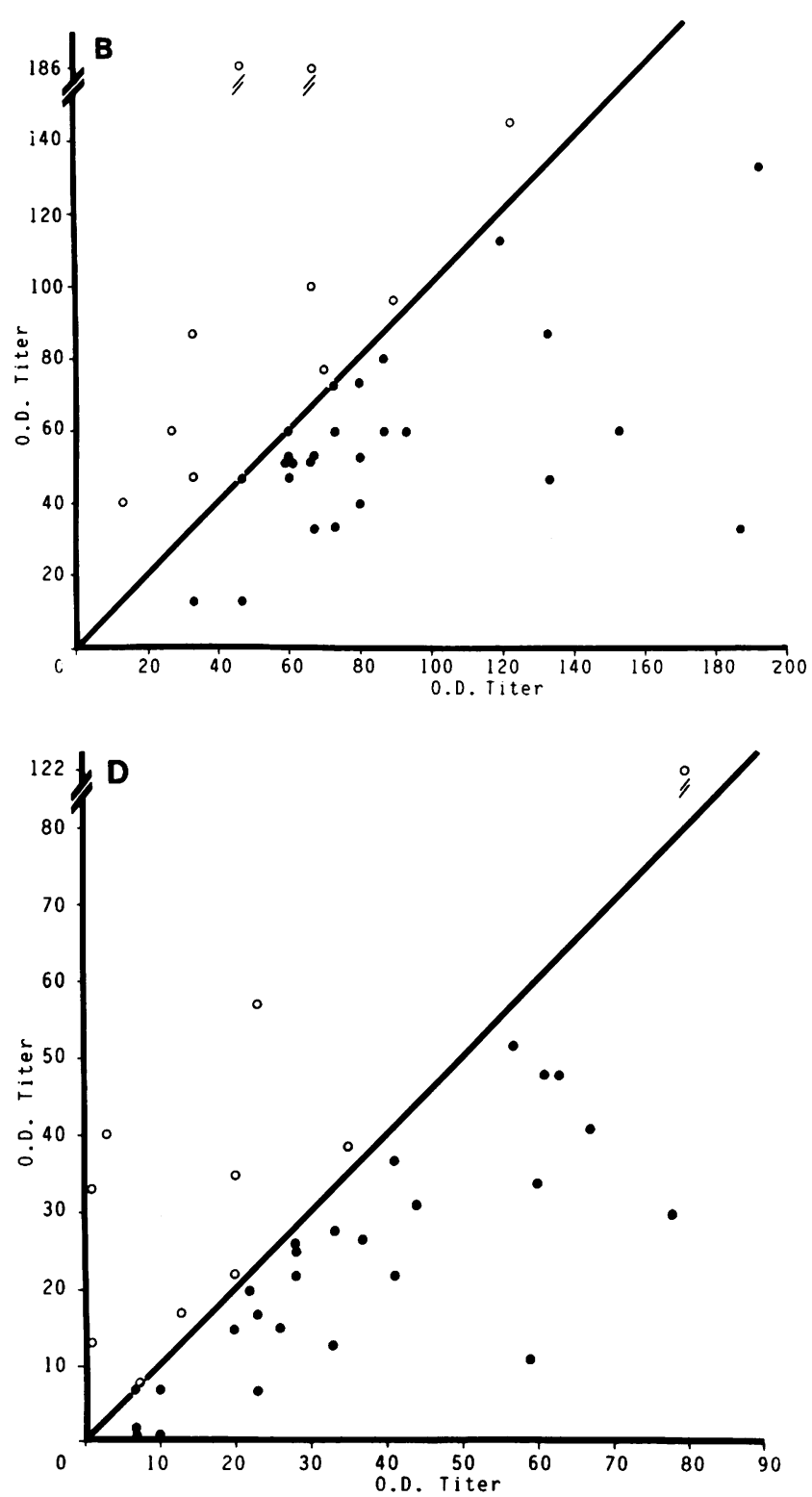

$F, 4.85$ (1.63); $P<0.025$ (NS). MZ: $r, 0.16$ (0.27); $F, 1.39$ (1.76); $P$ NS (NS). (D) IgA anti-type 14 Pn. DZ: $r, 0.68(0.57) ; F, 5.28$ (3.66); $P<0.01$ (<0.05). MZ: $r, 0.57$ (0.73); $F, 3.63$ (6.48); $P<0.001$ $(<0.001)$. 

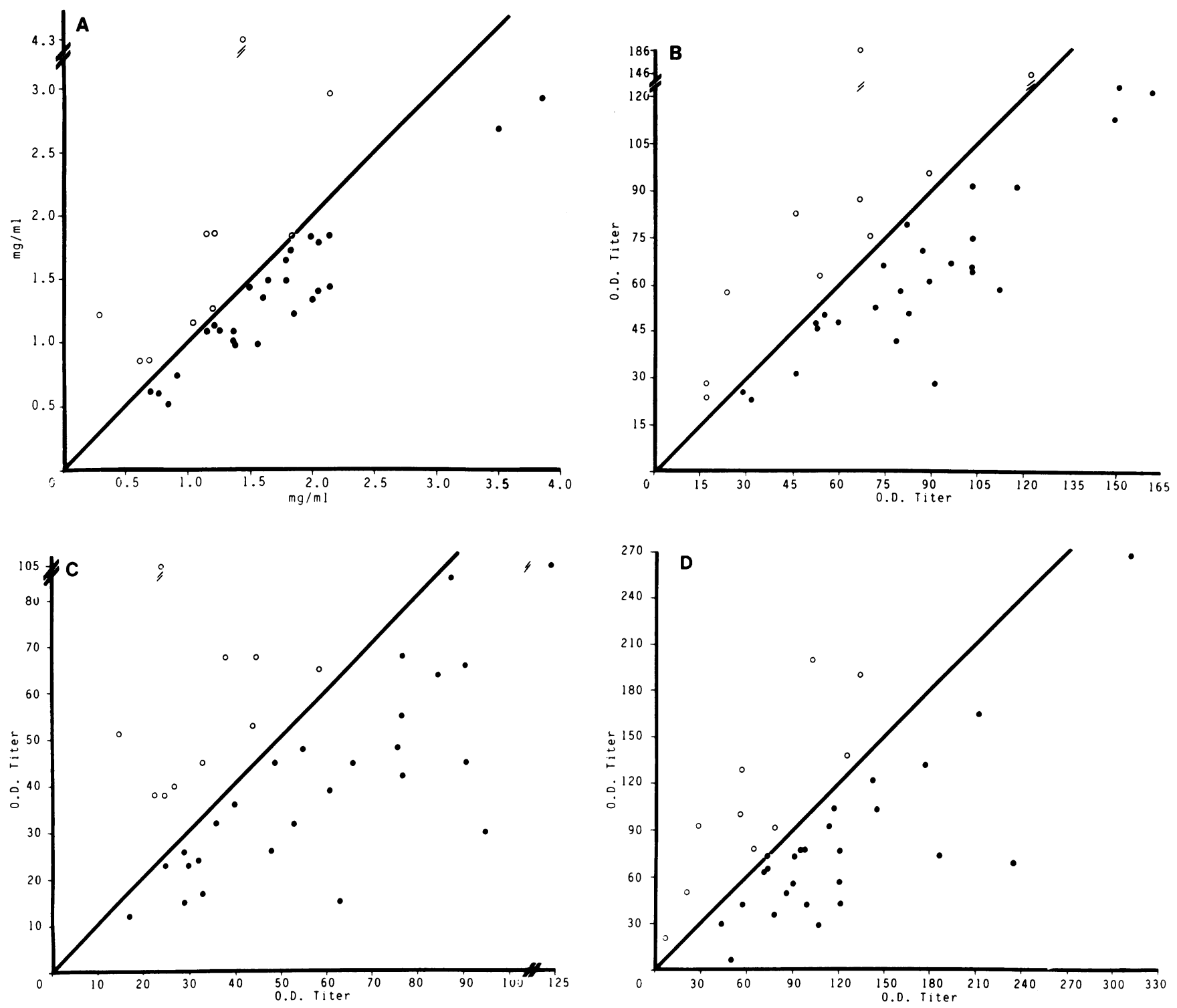

Figure 3. Comparison of IgM in twins reared apart. See Fig. 1 for explanation of symbols, etc. $(A)$ Total IgM. DZ: $r, 0.35 ; F, 2.1 ; P$, NS. MZ: $r, 0.82 ; F, 9.65 ; P<0.001$. (B) IgM anti-tetanus toxoid. DZ: $r, 0.54$ (0.55); $F, 3.34$ (3.42), $P<0.05$ (<0.05). MZ: $r, 0.59$ (0.31); $F, 3.82$ (1.88); $P<0.001$ (NS). (C) IgM anti-polyvalent Pn.

not significantly correlated: $\operatorname{IgG}(r=-0.40), \operatorname{IgA}(r=0.34)$, and $\operatorname{IgM}(r=0.35){ }^{2}$

Isotypic antibody titers. Anti-tetanus toxoid titers (Figs. 1 $B, 2 B$, and $3 B$ ) were highly correlated in the $\mathrm{MZ}$ twins for $\operatorname{IgG}(r=0.72, P<0.001)$ and $\operatorname{IgM}(r=0.59, P<0.001)$, but not for IgA $(r=0.25)$. In the DZ twin pairs, IgM titers $(r=0.54, P<0.05)$ were significantly correlated but not IgG $(r=0.27)$ or IgA $(r=0.17)$. Anti-polyvalent Pn titers (Figs. 1 $C, 2 C$, and $3 C$ ) in the $\mathrm{MZ}$ twin sera pairs were significantly correlated for $\operatorname{IgG}(r=0.52, P<0.01)$ and $\operatorname{IgM}(r=0.59$, $P<0.001)$, but not for IgA $(r=0.16)$, while the intrapair correlations in the $\mathrm{DZ}$ twins was significant for $\operatorname{IgA}(r=0.66$, $P<0.025)$ but not for $\operatorname{IgG}(r=0.37)$ nor $\operatorname{IgM}(r=-0.18)$.

2. A summary of each twin's Ig and isotypic antibody titers and specific activity results, along with demographic data, are available from Dr. Kohler on request.

DZ: $r,-0.18(0.58) ; F, 0.70$ (3.79); $P$, NS (<0.05). MZ: $r, 0.59$ (-0.01); $F, 3.88$ (0.98); $P<0.001$ (NS). (D) IgM anti-type $14 \mathrm{Pn}$. DZ: $r, 0.58$ (0.04); $F, 3.73$ (1.08); $P<0.05$ (NS). MZ: $r, 0.60$ (0.22); $F, 4.01$ (1.55); $P<0.001$ (NS).

Figs. $1 D, 2 D$, and $3 D$ show that anti-type 14 Pn antibody in the MZ twins was significantly correlated for all three isotypes: $\operatorname{IgG}(r=0.60, P<0.001), \operatorname{IgA}(r=0.57, P<0.001)$, and $\operatorname{IgM}(r=0.60, P<0.001)$. In the $\mathrm{DZ}$ twins, a significant correlation was found for $\operatorname{IgA}(r=0.68, P<0.01)$ and $\operatorname{IgM}$ $(r=0.58, P<0.05)$ anti-type 14 Pn but not for IgG $(r=0.17)$.

Specific activity of antibody. When the isotypic antibody levels were expressed in terms of specific activity rather than total antibody, the within pair $F$-ratio and correlation increased in the $\mathrm{MZ}$ group for IgG anti-poly Pn (0.52 to 0.61$)$ but not for anti-type $14 \mathrm{Pn}$ or tetanus toxoid, and for all IgA antibodies (anti-poly Pn [0.16 to 0.27], anti-type 14 [0.57 to 0.73], and anti-tetanus toxoid [ 0.25 to 0.53$]$ ). No increases in $F$ and $r$ occurred when IgM antibody was calculated in terms of specific activity. In the DZ group, the intrapair specific activity correlations were increased for IgA anti-tetanus $(0.17$ to 0.24$)$ 
and for IgM anti-poly Pn ( -0.18 to 0.58$)$ antibodies. The specific activity results are shown in parenthesis in Figs. 1-3.

Essentially no change in results occurred when one MZ twin was randomly eliminated from each set of triplets to yield one $M Z$ pair from the $M Z$ triplets and one $M Z$ and one $D Z$ pair from the unlike sex triplets ( $\mathrm{MZ}$ sisters and brother).

\section{Discussion}

Our results indicate that genetic factors are more important than environmental exposures in determining total Ig and specific antibody levels in man. Overall, the within twin pair concentrations of total IgG, IgA, and IgM and isotype antibody titers were significantly correlated in the $\mathrm{MZ}$ but not the $\mathrm{DZ}$ twins, despite growing up in different environments. The average age at separation was 2 mo and by history each individual twin had been immunized with tetanus toxoid but not pneumococcal polysaccharide vaccine. Presumably, by age 11 , all subjects had variable but sufficient natural exposure to multiple different Pn serotypes; however, despite this exposure, polyvalent and type 14 antibody titers were more significantly correlated in the $\mathrm{MZ}$ than in the $\mathrm{DZ}$ twins. The fact that significant correlations occurred in four of nine antibody titers in DZ twins compared with seven of nine in $\mathrm{MZ}$ twins indicates a genetic influence in the former group also (Table I). The presence of rheumatoid arthritis and multiple sclerosis in single members of two $\mathrm{DZ}$ female twin pairs could not explain the differences observed in $\mathrm{DZ}$ within pair total Ig concentrations and isotypic antibody levels.

Previous investigations have been limited to total Ig levels in twins reared together and most have demonstrated a significant $\mathrm{MZ}$ within pair correlation of $\operatorname{IgG}, \operatorname{IgA}$, and IgM in addition to $\mathrm{IgD}$ and $\mathrm{IgE}$ concentrations when compared with DZ twin sera $(4-6,11,12)$. Since the same environment was shared by these twins, it can be assumed that, overall, cumulative antigenic exposure was also similar. A primary genetic influence on total Ig concentrations was suggested by the more closely correlated levels in the $\mathrm{MZ}$ twins. Specific antibody levels were not measured in these studies and any potential within pair environmental effects were not discernible.

There are few studies concerning genetic influence on specific antibody levels in humans. One recent study reported higher total antibody responses to group B meningococcal polysaccharide vaccination in persons with the KM (1) kappa light chain allotype, a gene product of human chromosome 2 (13). A second study reported significantly higher IgG antigliadin antibody in patients with gluten-sensitive enteropathy who were $\mathrm{G} 2 \mathrm{M}(\mathrm{N})$-positive than in $\mathrm{G} 2 \mathrm{M}(\mathrm{N})$-negative patients, despite the fact that both groups were on a gluten-free diet

Table I. Distribution of Significance (P) Values for Isotypic Antibody Titers in Twins Reared Apart

\begin{tabular}{lll}
\hline$P$ & MZ & DZ \\
\hline NS & 2 & 5 \\
0.05 & - & 2 \\
0.025 & - & 1 \\
0.01 & 1 & 1 \\
0.001 & 6 & - \\
\hline
\end{tabular}

(14). G2M(N) is an IgG heavy chain allotype coded for by a gene on chromosome 14. There was no association of antigliadin antibody with the chromosome 6 coded major histocompatibility complex class I and II antigens, B8 and DR3. IgE antibody to ragweed and grass pollens are also influenced by genetic factors $(15,16)$.

In spite of different environmental exposures to antigens, the predominant factor(s) determining total Ig and isotypic antibody levels in these twins was genetic rather than environmental. We postulate that sufficient cumulative natural exposure to Pn capsular polysaccharides had occurred to initiate antibody synthesis and that genetic factors were responsible for the significant correlations in anti-Pn antibody levels in the $\mathrm{MZ}$ twins. If so, in very young $\mathrm{MZ}$ twins with different cumulative environmental exposures, antibody titers would be less highly correlated. When antibody titers were compared in the $\mathrm{MZ}$ twins under age 25 to those over age 50, there were no differences in the correlations. However, IgG anti-tetanus titers but not anti-poly Pn or anti-type 14 IgG titers were found to be inversely correlated with age presumably because puncture wounds treated with booster tetanus toxoid immunizations occur less frequently with advancing age. The occasional large differences in intra MZ twin pair isotypic antibody titers are best explained by marked variation in tetanus toxoid immunizations and natural exposure to Streptococcus pneumococci which outweighed genetic influences. Since the $\mathrm{MZ}$ within pair correlations were higher for total $\mathrm{Ig}$ concentrations $(0.65$ to 0.82 ) than for IgM and IgG antibody titers (0.52 to 0.72$)$, and were usually lower for within pair antibody specific activity, this genetic regulation may influence total Ig concentrations more than concentrations of isotypic antibody. We predict that antibody responses to immunization with defined antigens would show an even greater correlation of within pair responses in $\mathrm{MZ}$ twins. It is important to note, however, that the general health of each twin, as well as zygosity, will also be an important regulatory influence since total Ig and isotypic antibody levels differ greatly in $\mathrm{MZ}$ twins who are discordant for systemic lupus erythematosus or the acquired immune deficiency syndrome (P. F. Kohler, unpublished observations).

\section{Acknowledgments}

Our sincere thanks to Ms. Patt Anderson for technical help, Ms. Kathy Utschinski for graphics and manuscript preparation, and Dr. Gary Zerbe for advice on statistical analysis. The type 14 Pn polysaccharide was generously provided by Lederle Research Laboratories, Pearl River, NY. We thank Dr. Andrew Saxon and Dr. Gerald Shiffman for quantitative analysis of antibody in the standard serum. Dr. Janet Stewart's and Dr. Henry Claman's critical review of the manuscript is appreciated.

This work was supported in part by National Institutes of Health training grant AI-07166, the Clinical Immunology Research Fund, National Science Foundation, Spencer Foundation, Pioneer Fund, and Harcourt, Brace and Jovanovich, Inc.

\section{References}

1. Sang, J. H., and W. R. Sobey. 1954. The genetic control of response to antigenic stimuli. J. Immunol. 72:52-65.

2. Bluestein, H. G., I. Green, and B. Benacerraf. 1971. Specific immune response genes of the guinea pig. J. Exp. Med. 134:458-481.

3. Gustafsson, B. E., and C. B. Laurell. 1959, Gamma globulin 
production in germ-free rats after bacterial contamination. J. Exp. Med. 110:675-684.

4. Kalff, M. W., and W. Hijmans. 1969. Serum immunoglobulin levels in twins. Clin. Exp. Immunol. 5:469-477.

5. Allansmith, M., B. McClellan, and M. Butterworth. 1969. The influence of heredity and environment on human immunoglobulin levels. J. Immunol. 102:1504-1510.

6. Carbonara, A. O., R. Cepellini, W. Yount, and S. Landucci. 1970. The serum Ig level in human twins. Acta Genet. Med. Gemellol. 19:238.

7. Bouchard, T. J., Jr., L. L. Heston, E. D. Eckert, M. Keyer, and S. Resnicks. 1981. The Minnesota study of twins reared apart: project description and sample results in the developmental domain. In Twin Research 3: Part B. Intelligence, Personality and Development. L. Zedda, P. Parisi, and W. E. Nace, editors. Alan R. Liss, Inc., New York. 227-233.

8. Lykken, D. T. 1978. The diagnosis of zygosity in twins. Behav. Genet. 8:437-473.

9. Gray, B. M. 1979. ELISA methodology for polysaccharide antigens: protein coupling of polysaccharides for adsorption to plastic tubes. J. Immunol. Methods. 28:187-192.
10. Vogel, D., and A. G. Motulsky. 1979. In Human Genetics: Problems and Approaches. Springer-Verlag New York, Inc., New York. 488.

11. Rowe, D. S., J. A. Boyle, and W. W. Buchanan. 1968. Plasma immunoglobulin concentrations in twins. Clin. Exp. Immunol. 3:233244.

12. Lee, S. K., J. D. Metrakos, K. R. Tanaka, and D. C. Heiner. 1980. Genetic influence on serum IgD levels. Pediatr. Res. 14:60-63.

13. Pandey, J. P., W. D. Zollinger. H. H. Fudenberg, and C. B. Loadholt. 1981. Immunoglobulin allotypes and immune response to meningococcal group B polysaccharide. J. Clin. Invest. 68:1378-1380.

14. Weiss, J. B., R. K. Austin, M. S. Schanfield, and M. F. Kagnoff. 1983. Gluten-sensitive enteropathy: immunoglobulin $G$ heavy-chain $(\mathrm{Gm})$ allotypes and the immune response to wheat gliadin. J. Clin. Invest. 72:96-101.

15. Levine, B. B., R. H. Stember, and M. Fotino. 1972. Ragweed hayfever: genetic control and linkage to HL-A haplotype. Science (Wash. DC). 178:1201-1203.

16. Marsh, D. G., W. B. Bias, and K. Ishizaka. 1974. Genetic control of basal serum immunoglobulin $\mathrm{E}$ level and its effect on specific reaginic sensitivity. Proc. Natl. Acad. Sci. USA. 71:3588-3592. 